\title{
Editorial
}

\section{Tax Simplification}

\section{J. David B. Oliver, Coopers \& Lybrand, London}

A growing topic of discussion is the subject of tax simplification. Two recent reports in the $\mathrm{UK}^{1}$ have added to the debate and so have proposals in the US for a flat rate income tax. Significant steps are being taken in Australia and New Zealand to rewrite their tax legislation, which in the case of Australia is based on a statute which now has section numbers as unmanageable as, for example, s.159GZZZZA(2)(b)(iii)(B) Income Tax Assessment Act 1936. Compare this complexity with the enduring relative simplicity of the US Internal Revenue Code - and of course the complexities of the US regulations.

Sweden, France and Germany each have programmes or reviews which deal with the whole of their primary legislation. Denmark, Spain and the USA have initiatives which target specific tax areas while Canada now releases new tax legislation in draft for public consultation. ${ }^{2}$

Is it possible to rewrite tax legislation in such a way that it becomes less opaque? It would seem that some countries believe that it is possible: others, however, have managed to retain a relatively clear language for the statutes and have relied on interpretation by the courts to supply additional meaning to the text whether by abuse of rights tests or an interpretation based on the object and purpose of the legislation. There may therefore be more than one path to simplification.

Where the path chosen is a rewriting of the legislation, significant difficulties must be overcome. The new legislation, if adopted piecemeal, sits uneasily with the old. The alternative of waiting until rewriting is complete carries a risk that this will take too long and require too many resources and consistent political will over an extended period to see it through. How can the value of precedent, in particular past decisions in the courts on particular issues, be maintained when the new legislation is adopted? Are there key words and phrases from the old legislation which should be retained in the new legislation?

Meanwhile a flat rate income tax, or 'flat tax', is perhaps better seen as a development of the 'broaden the base, lower the rate' movement which has been fashionable since 1984. How is the lowering of the rate of tax to be financed? By broadening the base of course, which means removing most, if not all, allowances or deductions. The lower rate looks attractive but what happens if someone finds that they can no longer deduct their interest outgoings, or their health insurance premiums, or their charitable giving? Do they protest and insist that such categories of relief are fully justified and should be preserved and then bring pressure to bear on the politicians to preserve various deductions with the result that there is a vast amount of lobbying which ultimately results in inaction or the need to plug the revenue shortfall by increasing other taxes? We shall have to wait and see.

At first sight, of course, a flat rate tax looks attractive, and indeed VAT is in some countries a good example of just such a tax; so do proposals for rewriting tax legislation in simpler terms. But in both cases it is important to give proper weight to the factors which have led to the present position. Two of the most important factors must be the growth in cross-border trade and deregulation. Deregulation has been particulary influential. It has brought the relaxation of exchange control restrictions with the consequent introduction of anti-avoidance legislation in relation to, for example, controlled foreign companies, etc.; it has brought vastly increased foreign exchange dealings together with the creation of new financial instruments and techniques and the need to accommodate these within the tax system. A further factor in some countries has been the political desire to achieve equity within the tax system, to block loopholes whether by specific legislation or by a general anti-avoidance rule.

In any discussion of tax simplification it is therefore important to understand what is meant by the term because it is likely to vary from country to country. Three aspects of it have been

1 Inland Revenue: The Path to Tax Simplification: (i) A Report Under Section 165 Finance Act 1995 (HMSO, London) and (ii) A Background Paper (HMSO, London); Tax Law Review Committee: Interim Report on Tax Legislation (Institute for Fiscal Studies, London).

2 The Path to Tax Simplification, A Background Paper, op. cit. at p. 79. 
discussed above: tackling the drafting of legislation, looking at the approach to the interpretation of the legislation, and a flat tax. There are no doubt other aspects too, which may embrace simpler compliance rules or a self-assessment system, for example. But whatever it is understood to be the requisite changes to achieve it will ultimately be the responsibility of politicians rather than tax advisers or tax administrators. Moreover, according to the nature of the reform, the necessary changes may depend on the exercise of political will, or sometimes selfrestraint, over an extended period of time. It is therefore as much a challenge to politicians as to tax professionals. 